\title{
Enhancing Effects of Environmental Enrichment on the Functions of Natural Killer Cells in Mice
}

\section{OPEN ACCESS}

Edited by:

Yoshiro Kobayashi,

Toho University, Japan

Reviewed by:

Robert J. Canter,

University of California, Davis,

United States

Lora Petrie-Hanson,

Mississippi State University,

United States

Yu Gan,

Shanghai Cancer Institute, China

*Correspondence:

Lei Cao

lei.cao@osumc.edu

${ }^{\dagger}$ Present address:

Run Xiao,

The Cancer Hospital of the University of Chinese Academy of Sciences

(Zhejiang Cancer Hospital), Institute of Basic Medicine and Cancer (IBMC),

Chinese Academy of Sciences,

Hangzhou, China

Specialty section: This article was submitted to Molecular Innate Immunity, a section of the journal

Frontiers in Immunology

Received: 15 April 2021 Accepted: 14 July 2021

Published: 28 July 2021

Citation:

Xiao R, Ali S, Caligiuri MA and Cao L (2021) Enhancing Effects

of Environmental Enrichment on the Functions of Natural

Killer Cells in Mice.

Front. Immunol. 12:695859. doi: 10.3389/fimmu.2021.695859

\author{
Run Xiao ${ }^{1,2 \dagger}$, Seemaab Ali ${ }^{1,2,3}$, Michael A. Caligiuri ${ }^{4}$ and Lei Cao ${ }^{1,2 *}$ \\ 1 Department of Cancer Biology and Genetics, College of Medicine, The Ohio State University, Columbus, \\ $\mathrm{OH}$, United States, ${ }^{2}$ The Ohio State University Comprehensive Cancer Center, The James Cancer Hospital and Solove \\ Research Institute, Columbus, $\mathrm{OH}$, United States, ${ }^{3}$ Medical Scientist Training Program, The Ohio State University, \\ Columbus, $\mathrm{OH}$, United States, ${ }^{4}$ Department of Hematology \& Hematopoietic Cell Transplantation, City of Hope National \\ Medical Center and the Beckman Research Institute, Los Angeles, CA, United States
}

The environment of an organism can convey a powerful influence over its biology. Environmental enrichment (EE), as a eustress model, has been used extensively in neuroscience to study neurogenesis and brain plasticity. EE has also been used as an intervention for the treatment and prevention of neurological and psychiatric disorders with limited clinical application. By contrast, the effects of EE on the immune system are relatively less investigated. Recently, accumulating evidence has demonstrated that EE can robustly impact immune function. In this review, we summarize the major components of EE, the impact of EE on natural killer (NK) cells, EE's immunoprotective roles in cancer, and the underlying mechanisms of EE-induced NK cell regulation. Moreover, we discuss opportunities for translational application based on insights from animal research of EEinduced NK cell regulation.

Keywords: environmental enrichment (EE), immune function, natural killer (Nk) cell, BDNF, HPA axis, sympathetic nervous system, cancer

\section{INTRODUCTION}

The environment of an organism can convey a powerful influence over its biology and physiology. How different environments influence health outcomes is studied in part within the field of stress research. For most applications, stressors can be categorized as one of two types: distress and eustress. "Stress" most commonly refers to distress, a negative or maladaptive state which poses a risk to health and well-being (1). Relatively speaking, eustress is a less commonly used term that relates to milder and/or briefer challenges, which are manageable and induce a positive or healthy, adaptive response $(2,3)$. Most stress research has focused on the impact of distress on health. The impact of eustress, which is associated with health benefits, has been attracting attention in recent years.

One of the most widely used eustress models in laboratory rodents is environmental enrichment (EE). The beneficial effects of EE have been explored through a long history of research. Initially, EE was used extensively in neuroscience as a model for neurogenesis, brain plasticity, and learning and memory, as well as a tool for the treatment and prevention of neurological and psychiatric disorders (4-6). Apart from the studies in earlier years identifying the effects of EE on the nervous system, follow-up research has shown that $\mathrm{EE}$ also exerts a significant influence on other systems such as the 
endocrine system and the immune system (7-9). Accumulating evidence has shown that EE profoundly influences the immune system. Here we summarize the components of EE and EE's effects on immune cells. We focus on the impact of EE on natural killer (NK) cells, in particular the EE-induced protective roles of $\mathrm{NK}$ cells in cancer. We also discuss the underlying mechanisms of EE-induced NK regulation, and briefly consider the potential implications of $\mathrm{EE}$ research for translational interventions in human health and disease.

\section{WHAT IS ENVIRONMENTAL ENRICHMENT?}

Donald Hebb was the first to propose EE as an experimental tool as early as the late 1940s (10-12). Hebb performed foundational studies to discover the connection between $\mathrm{EE}$ and improvement in cognition and behavior. Although in these initial studies the beneficial effects of EE were examined from the perspective of the nervous system, follow-up studies have found that EE's effects are more systemic and complicated than initially conceived.
In the experimental laboratory setting, an "enriched environment" is compared with a "standard environment (SE)". Although the settings of EE vary in different laboratories, generally speaking, they have the same components. Compared with SE, EE is defined as housing enrichments with increased space, physical activity, and/or social interactions that confer enhanced sensory, cognitive, motor, and social stimulation (4). In our studies (Figure 1), we house control mice in standard laboratory cages of $30.5 \mathrm{~cm} \times$ $17 \mathrm{~cm}$, at 5 mice per cage with nesting material. In comparison, EE mice are housed in a larger cohort of 10-20 mice in a bigger cage, $1.5 \mathrm{~m} \times 1.5 \mathrm{~m}$, supplemented with running wheels, tunnels, igloos, huts, retreats, wood toys, a maze, and nesting material (13). In addition, the supplemental items in EE cages are exchanged or rearranged once a week over the period of the experiments to provide for increased novelty and complexity in the space.

\section{THE MAJOR COMPONENTS OF ENVIRONMENTAL ENRICHMENT}

EE consists of environments which provide physical enrichment (the cages contain running wheels for voluntary exercise), social

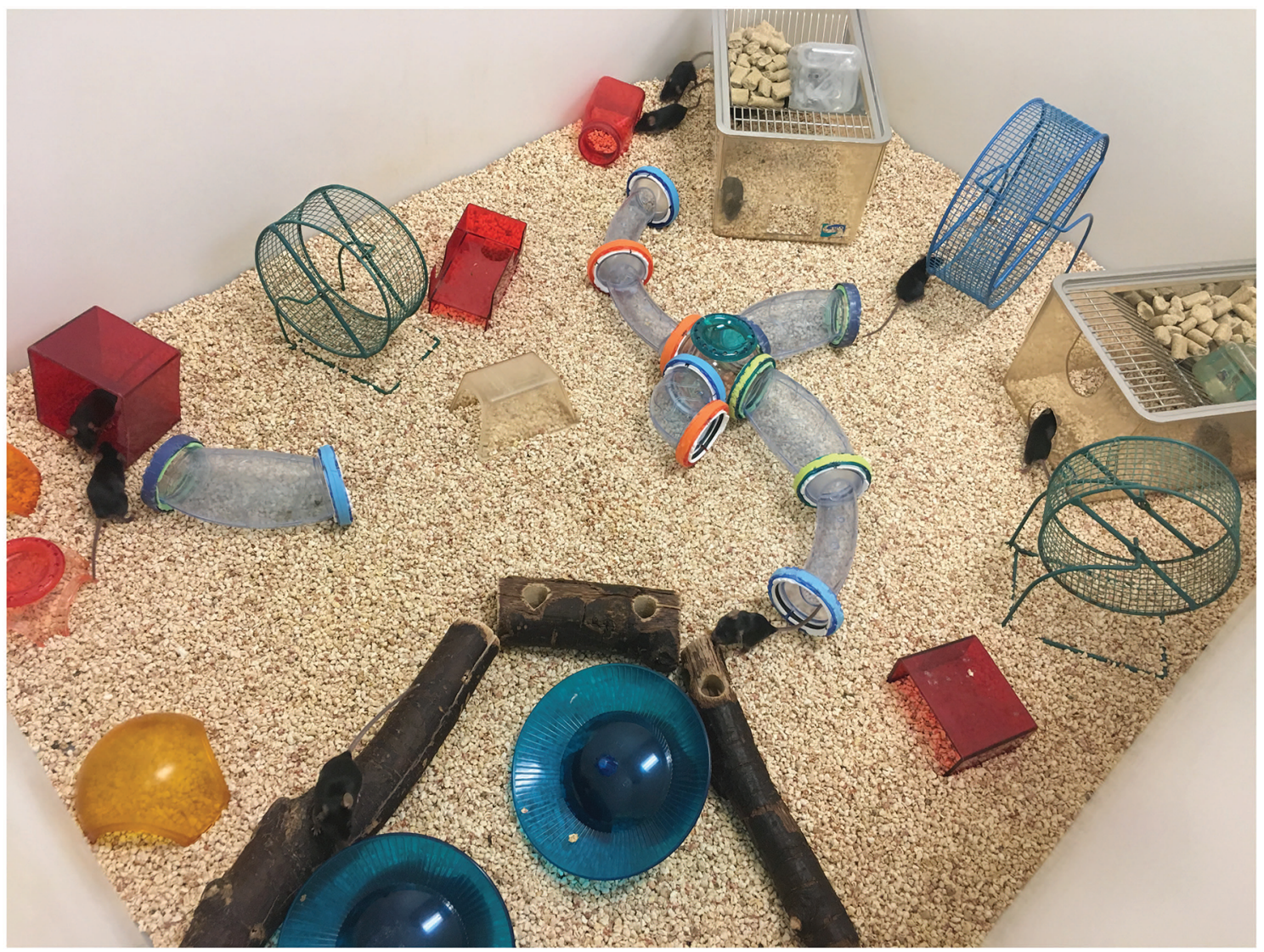

FIGURE 1 | A typical EE setting. The precise paradigm implemented in studies of EE varies both from lab to lab, but key features are generally similar. In contrast to standard housing, EE is a bigger cage supplemented with running wheels, tunnels, igloos, huts, retreats, wood toys, a maze, and nesting material. The supplements in EE cage are exchanged or rearranged once a week over the period of the experiments. 
enrichment (the animals are placed in larger groups per cage), and cognitive and sensory enrichment (the animals are provided with a variety of objects to interact with, tunnels, and spaces to navigate) (14). These three components are key features of an EE for rodents. Therefore, the question is often raised as to which components are important for eliciting specific beneficial effects of EE. The importance of individual components of EE has been tested previously. Our studies and studies from other groups support the view that a single contributing factor of EE cannot be easily isolated for most of EE's beneficial effects (15-18). Instead, the components of EE work together to exercise overlapping, unified, or emergent effects on rodents living within it. Any one of these components cannot account for all of the effects of EE, thereby supporting the description of EE as "a combination of complex inanimate and social stimulation" (19). The individual impacts of physical enrichment, social enrichment, and cognitive and sensory enrichment, as they compare to the impact of combined EE, are described below.

\section{Physical Enrichment}

Similar to EE, physical exercise has been shown to enhance immune function (20) and to decrease body fat (21). To investigate whether physical exercise could alone account for the EE-induced phenotypes, we provided mice with access to voluntary wheel running. Wheel running led to physiological changes including reduced adiposity, and increased lean mass similar to that observed in the EE mice $(15,16)$. However, EE and wheel running also exhibited several differences as described below. EE was associated with altered adipokine levels in serum characterized as a decrease of leptin while an increase of adiponectin. The sharp drop ofleptin was identified as a key mediator of EE's anticancer effect (15). Runners displayed a pattern of adipokines quite distinct to that of EE with no change in serum leptin level and a decreased serum adiponectin. Moreover, running influenced gene expression in the arcuate of hypothalamus with a pattern that was qualitatively different than EE. In contrast to the EE mice whose brain-derived neurotrophic factor $(B d n f)$ expression was increased 3 -fold at 4 weeks of EE, running did not upregulate $B d n f$ significantly. Instead, the two orexigenic peptides neuropeptide $\mathrm{Y}(N p y)$ and agouti-related peptide (Agrp) were increased by wheel running. Lastly, although enhanced innate immune cytotoxicity was observed in both runners and EE mice, exercise alone did not significantly reduce tumor weight as EE achieved. These differences were not due to higher physical activity in EE. In fact, mice living in cages with free access to running wheels ran approximately $2 \mathrm{~km}$ per day. In comparison, EE mice traveled a mean total distance of $0.64 \mathrm{~km}$ per day, which is approximately one third of distance the runners traveled (15). Additional studies $(16,18)$ further support the notion that physical exercise alone is insufficient to account for EE-induced phenotypes, including tumor resistance, although it likely contributes to these outcomes.

\section{Social Enrichment}

Social enrichment is a significant contender to account for many of the effects of EE. In fact, some studies identify social enrichment as capable of reproducing specific neurobiologic effects of EE. For example, Moreno-Jiménez and colleagues have shown the social component of EE to be as potent a stimulus of adult hippocampal neurogenesis as EE (22). However, a study by Rosenzwig et al. lead to the opposite conclusion (19). In that study, authors tested whether mere group living (social stimulation) is the major contributor of EE to measures of brain anatomy and brain chemistry that develop in $\mathrm{EE}$ animals. In detail, one control group of 12 male rats were assigned to a large cage without stimulus objects (19). These stimuli were the only difference when compared with the EE setting cohort. After onemonth duration, measures were taken of weights of brain regions, RNA and DNA contents of regions of cerebral cortex, and acetylcholinesterase activities of brain regions. Although the cage size and the number of rats housed together were the same between the EE group and corresponding control group, the results of the cerebral measures differ considerably as a consequence of the inanimate stimulus (19). These observations suggest living in the same-sized group and in the same-sized cage is less effective at altering the brain than doing so with inanimate enrichment. Taken together, social enrichment alone is not sufficient to reproduce all of the cerebral effects of $\mathrm{EE}(11,19)$.

\section{Cognitive and Sensory Enrichment}

There are few studies to directly compare the specific effect of cognitive and sensory enrichment with the typical complex EE setting. We can distinguish the differences between them from separate parallel studies which have tested the impact of either cognitive stimulation or EE on progression of the same disease in murine model. Specifically, Jankowsky et al. showed that EE conferred a beneficial effect in a mouse model of Alzheimer's disease by mitigating cognitive deficits (23). In sharp contrast, environmental novelty alone exacerbates stress hormones and A $\beta$ pathology in an Alzheimer's model (24). In addition, it has been shown that observing an enriched environment without being allowed active participation, does not elicit the cerebral effects of EE (25). These contrasting results suggest cognitive enrichment alone cannot account for EE. Altogether, these studies have revealed that no single variable can account for the multifaceted consequences of enrichment. Instead, each of these components of EE interact in complex ways.

Other factors which we have not listed also contribute to the effects of EE. Of note, the length of an EE exposure can greatly impact observed outcomes: the phenotypes of EE do not show up at the same time. The durations for EE exposure used in mouse studies are mostly from one week to a couple of months. EE is also delivered either continuously, as in continuous EE housing, or at interval exposures, such as daily for a few hours. EE increases adipose NK cell percentage after two-weeks exposure (26). In contrast, EE decreases systemic leptin levels after a longer duration, more than four weeks (15). In addition, 5-week EE exhibits stronger anticancer effect than 3-week EE. These data suggest duration of EE exposure impact the EE' phenotype.

\section{ENVIRONMENTAL ENRICHMENT INFLUENCES NK CELL FUNCTION}

Increasing evidence has shown that EE produces notable effects on the phenotype and function of immune cells in mice. Take $\mathrm{T}$ 
cells for example: exposure to an EE for merely 1 week is sufficient to increase the frequency of single positive (SP) $\mathrm{CD}^{+} \mathrm{T}$ cells and decrease the frequency of SP CD4 ${ }^{+} \mathrm{T}$ cells, thereby decreasing the $\mathrm{CD} 4: \mathrm{CD} 8$ ratio in both thymus and spleen $(27,28)$. In addition to influencing adaptive immune cells, EE also impacts innate immune cells. Analysis of peripheral blood samples from mice after a two week EE exposure shows no difference in total numbers of blood leukocytes or individual leukocyte populations (29). However, EE mice display a significant difference in their relative proportions of leukocyte populations, characterized by a higher proportion of neutrophils and a correspondingly lower proportion of lymphocytes compared to SE mice, suggesting myeloid cells are responsive to EE (29). Studies of EE's effects on macrophages have been reported, as well (30). Here we focus on the effects of EE on NK cell function.

\section{Impact of EE on NK-Cell Maturation}

NK cells are innate immune cells that are sensitively responsive to internal or external stimuli $(31,32)$. Mouse NK cells undergo a maturation process that is defined by expression of the surface markers CD27 and CD11b. Developing NK cells are classified as precursor (stage I, CD $11 b^{\text {low }} \mathrm{CD} 27^{\text {low }}$ ), immature (stage II, $\left.\mathrm{CD} 11 \mathrm{~b}^{\text {low }} \mathrm{CD} 27^{\text {high }}\right)$, proinflammatory (stage $\mathrm{III}, \mathrm{CD} 11 \mathrm{~b}^{\text {high }}$ $\mathrm{CD} 27^{\text {high }}$ ), or cytotoxic (stage IV, CD11b ${ }^{\text {high }} \mathrm{CD} 27^{\text {low }}$ ) (33). As NK cells progress through these stages of maturation, they gradually lose their proliferative capability (34). EE promotes the terminal maturation of NK cells both centrally in the bone marrow and peripherally in the spleen and blood of tumor-free mice (35). NK cells with enhanced maturation have also been found in tumorbearing mice after EE exposure (35). The maturation of NK cells is crucial for the acquisition of optimal functional activity and for their immune response to tumors. As defined before, NK cells in stage II $\left(\mathrm{CD} 11 \mathrm{~b}^{\text {low }} \mathrm{CD} 27^{\text {high }}\right)$ and stage III $\left(\mathrm{CD} 11 \mathrm{~b}^{\text {high }} \mathrm{CD} 27^{\text {high }}\right)$ show the best capability of cytokine secretion, whereas NK cells in stage IV (CD11 $\mathrm{b}^{\text {high }} \mathrm{CD} 27^{\text {low }}$ ) exhibit the greatest cytolytic function (36).

\section{Impact of EE on NK-Cell Proliferation}

$\mathrm{EE}$ increases $\mathrm{CD} 27^{+}$immature and proinflammatory NK-cell proliferation in the bone marrow and blood of tumor-free mice (35). In contrast, EE increases splenic $\mathrm{CD} 27^{+}$immature and proinflammatory NK-cell proliferation in tumor-bearing mice, which in turn have a lower tumor burden. In agreement, splenectomy abrogates the EE-induced tumor-resistant phenotype (35) implicating splenocytes in tumor resistance. EE also impacts the recovery of NK cells after depletion (37). We observed a faster NK-cell recovery in the spleen, bone marrow and blood following depletion using anti-asialo-GM1 antibody (37).

\section{Impact of EE on NK-Cell Cytotoxicity}

Consistent with enhanced NK-cell maturation and proliferation, EE enhances NK-cell cytotoxicity in both tumor-free mice and tumor-bearing mice $(15,38)$. Song et al. report that NK-cellmediated immunity plays a critical role in EE-induced tumor inhibition in murine tumor models of pancreatic cancer and lung cancer (39). They identified certain markers associated with higher cytotoxic activity of tumor-infiltrating NK cells from EE mice. The expression of NKG2D, an activating cell surface receptor (40), on tumor-infiltrating NK cells is higher in EE mice (39). In addition, the expression of CD107a, a functional marker of NK-cell activation and cytotoxicity $(41,42)$, on tumorinfiltrating NK cells from EE mice is also significantly increased (39). Interestingly, a recent report shows that minimal cage enrichment provided by placing one mouse igloo within a standard cage can enhance the activation of NK cells relating to antitumor immunity in a murine ovarian cancer model (43). Collectively, these studies suggest a positive modulating effect of $\mathrm{EE}$ in promoting NK-cell maturation and cytotoxicity.

\section{Impact of EE on NK-Cell Infiltration Into Tumors}

As discussed above, EE exposure not only affects immunity under normal conditions, but also produces robust immune regulation under pathologic conditions. Song et al. reported that EE promoted tumoral infiltration of NK cells instead of T lymphocytes in a mouse model of pancreatic cancer (39). Both immunohistochemical analysis and flow cytometry analysis demonstrate more abundant tumoral NK cells from EE mice (39). EE upregulated the cell surface expression of the chemokine receptor CCR5 in blood- and tumor-derived NK cells, which plays an important role in the enhancement of tumoral NK-cell infiltration (39). In a murine model of glioma, EE increased NK cell accumulation at tumor site mediated by IL-15 (30).

\section{Impact of Experimental Context for EE on NK Cell Function}

Contextual factors, such as age, sex, and obesity, will play a major role in outcomes for any EE clinical interventions (as with any clinical intervention). These factors are known to have significant effects on immune function and particularly on NK cells (44-47). In animal studies modeling subgroups where deficits or health hazards are more pronounced (disease models for autism spectrum disorder, post-stroke, obesity, age-related disease, etc.), EE appears to have more substantial benefits. In these contexts, EE tends to improve outcomes and bring animals closer to their model control baselines - although the disease model and the context being studied matters significantly. With respect to NK cell activity, one animal study has identified a protective effect of a minimal type of EE on NK cell function during aging (8). Very old mice 20-22 months old show reduced NK cell-mediated lysis of tumor cells compared to adult and older middle-aged mice. This NK cytotoxicity deficit can be prevented by exposure to EE for 2-4 months starting at 20-22 months old.

\section{KEY MEDIATORS FOR ENVIRONMENTAL ENRICHMENT'S NK-CELL REGULATION}

Much of the research into the immune system or into the nervous system considers these systems separately, exerting their own functions independently. However, accumulating evidence has demonstrated substantial cross-talk between the nervous system and immune system, capable of inducing 
reciprocal action on one another $(48,49)$. Specifically, neurons can produce immune cytokines that act on immune cells, and immune cells can produce neurotransmitters and neuropeptides that act on neurons. Endocrine system also communicates and provides feedback between both the nervous system and the immune system through adipokines, cytokines, hormones, and other signaling molecules. Therefore, it is not surprising that EE, initially utilized as a neurological model, can robustly impact the immune system. Next, we summarize the key mediators involved in EE-induced immune regulation including NK cells.

\section{BDNF}

Our team was first to identify hypothalamic BDNF as a key regulatory molecule in $\mathrm{EE}(15,18)$. At an early time point of 2 weeks in EE, $B d n f$ upregulation was detected in the arcuate and ventromedial/dorsomedial hypothalamic nuclei (15). Importantly, hypothalamic gene delivery of BDNF mediated by an adeno-associated virus (AAV) recapitulated the mild activation of the sympathetic nervous system (SNS) and the hypothalamic-pituitary-adrenal axis (HPA) that are critical features of EE's phenotype. Consequently, this treatment reproduced the EE-induced anticancer effects seen in multiple murine cancer models. Furthermore, overexpression of hypothalamic BDNF reproduced EE-induced NK-cell phenotypes characterized with a high percentage of late-stage maturity of NK cells, whereas knockdown of hypothalamic BDNF abrogated EE-induced NK modulation (37). These data suggest hypothalamic BDNF is a mediator molecule for EEinduced NK cells. In addition, we reported hypothalamic BDNF was required for EE-induced $\mathrm{T}$ cell regulation in both primary and secondary lymphoid tissues $(27,28)$. Together these observations suggest hypothalamic BDNF as a critical immunomodulatory molecule in the brain, which increases in response to $\mathrm{EE}$ and which induces downstream immune changes. We have also investigated other molecules which are regulated in the hypothalamus of $\mathrm{EE}$ mice, none of which can recapitulate the peripheral phenotypic changes induced by EE in the way that hypothalamic BDNF can (50). This evidence strengthens the view of hypothalamic BDNF as a master gene coordinating the metabolic and immune regulatory effects of EE. Importantly, this pathway differs from the local mechanisms thoroughly elucidated by Garofalo et al., in which BDNF produced in the brain of EE mice modulates NK cell activation through IL-15 expressed by brain microglia in the context of glioma (51). It is likely that other molecules act selectively in extrahypothalamic brain regions, such as prefrontal cortex, contributing to EE's immune modulatory effects, warrant of further investigation.

\section{SNS}

A large body of stress research implicates two nervous system or neuroendocrine pathways which exert a regulatory effect on the immune system: the sympathetic nervous system (SNS) and the hypothalamic-pituitary-adrenal (HPA) axis (52, 53). EE can serve as a model of eustress-mild and manageable stress associated with benign or beneficial adaptations (54). EE functions through these two arms in order to regulate immune function. Through the SNS, all primary and secondary immune organs receive substantial innervation from sympathetic postganglionic neurons $(55,56)$. Norepinephrine (NE) binds to either $\alpha$ - or $\beta$-adrenergic receptors expressed on the surface of immune cells including NK cells, which induces changes in gene expression of various immune-cell-derived factors $(55,57)$. In agreement, we observed serum NE levels trending upward in EE mice (15). Studies using nonselective $\beta$ blocker administration inhibiting the SNS have shown that intact SNS is required for EEinduced NK-cell and T-cell phenotypes in the spleen $(27,39)$. Specifically, 6OHDA-induced sympathectomy eliminates the enhanced cytolytic activity and the increased expression of NKG2D and CCR5 in NK cells from EE mice (39), suggesting $\beta$-adrenergic receptor signaling regulates gene expression in NK cells that is related to NK cell function.

\section{HPA Axis}

Glucocorticoids play an important role in regulating the inflammatory and immune response. Glucocorticoids are used in medicine to treat diseases caused by various inflammatory and autoimmune disorders (58). All immune cells express glucocorticoid receptors (GR) and are responsive to glucocorticoids released by activation of the HPA axis, though GR expression and responsiveness vary (59). In our studies, the mRNA level of corticotropin-releasing hormone $(\mathrm{Crh})$ from EE mice was elevated in the hypothalamus (18). Glucocorticoid levels in the serum of EE mice were also mildly elevated, approximately $50 \%(15,28)$. Our data from thymocyte-specific GR knockout mice or adrenalectomized mice demonstrated that the EE-induced T-cell phenotypes in the thymus and spleen are dependent on the activation of the HPA axis $(27,28)$. Moreover, our preliminary data shows that adrenalectomy also abolishes the enhancement of NK cell maturation in EE, suggesting an important role of the HPA axis in EE-induced NKcell phenotypes. These data support a notion that HPA axis can exert a positive regulation on NK cell functions although glucocorticoids are shown to have an inhibitory effect on immune cell functions. We agree with the idea of Capellino et al. that the effects of glucocorticoids on NK cells depends on the concentration of glucocorticoid and the specific biological context (60). Of note, this does not mean that EE-induced immune regulation in every organ throughout the body is dependent on the HPA axis. For example, our unpublished data has also shown that EE increases the frequency of NK cells in adipose tissue, which is not abrogated by adrenalectomy. These data suggest that EE fine-tunes innate and adaptive immunities through a coordinated regulation of both arms of stress responses in a tissue-specific manner.

\section{Adipokines}

EE robustly reduces adiposity with little effect on body weight and enhances energy expenditure, leading to anti-obesity phenotype. The profound adipose remodeling induced by EE is also mediated by hypothalamic BDNF through a specific brainfat axis, the hypothalamic-sympathoneural-adipocyte (HSA) axis. One consequence of the HSA axis activation is the alteration of adipokine levels in the circulation $(15,18,54)$. EE regulates the expression and release of two major adipokines leading to a large decrease in serum leptin level up to 75\% (15), 
whereas an increase in adiponectin by $\sim 30 \%$ after 4 weeks of EE (15). Numerous studies have investigated the connection between these adipokines and regulation of immune cells (6163). Evidence has shown decreased leptin and increased adiponectin are correlated with an anti-inflammatory state. Of note, EE has been associated with suppression of proinflammatory marker expression $(16,64,65)$. However, the question of how these adipokines impact immune cells, including $\mathrm{NK}$ cells, in the context of EE remains unexplored and needs further investigation.

\section{Cytokines}

EE exposure reduces tumor size and the proliferation rate of glioma cells, and improves survival in an orthotopic glioma implantation model (30). Mechanistically, one of the pathways responsible for this benefit is EE-induced NK cell accumulation and activation mediated by an increase of IL-15 (30). IL-15 plays an important role in NK cell development and maturation (66, 67). Given that NK cells exhibited an enhanced maturation phenotype in EE mice, we speculate that EE-induced IL-15 may promote the maturation of NK cells.

Cytokines are involved in physical exercise-induced NK cell activation and inhibition of tumor growth. However, the underlying mechanism may be distinct between $\mathrm{EE}$ and physical exercise alone. For example, exercise-induced muscle-derived IL- 6 is involved in NK cell mobilization and redistribution during voluntary running (68). In contrast, in our preliminary data, we have not observed higher plasma IL-6 or higher expression of Il6 in muscle from EE mice. Cytokine profile analysis from serum samples is worth further investigation in order to identify further altered cytokine profiles between SE and EE mice that may mediate other effects on immune regulation. How cytokine alterations after EE affect immune cells is less well understood and should be explored.

\section{Eustress and Distress}

From the key mediators of EE, we note that some of them, such as the SNS and the HPA axis, are also involved in distress. Differences between $\mathrm{EE}$ as eustress and conditions of distress help us understand their outcomes. There are two aspects to consider. On one hand, certain key mediators are unique to EE. For example, higher expression of hypothalamic BDNF and decreased level of leptin are associated with EE, but not distress (15). On the other hand, the degrees of change in shared mediators stress responses are also different. Only a trend of increase in serum NE and a moderate increase ( $50 \%)$ of glucocorticoids are observed in EE mice $(15,28)$. In contrast, NE level and glucocorticoids increase by more than 2fold in distress models $(69,70)$. Therefore, we expect the extent of change in NE and glucocorticoid level is regulated by the valence of a stress response.

The differences in these underlying mechanisms of eustress and distress account for their divergent effects on NK cells. As we lay out above, EE generally exerts a positive regulatory action on NK cell function, by promoting the proliferation and terminal maturation of NK cells and enhancing NK cell cytotoxicity. In contrast, a prolonged stressor such as restraint stress diminishes NK cell function and suppresses expression of the cytokine genes involved in the recruitment and activation of NK cells (71).
Previous human NK cell studies have primarily identified chronic, prolonged distress will diminish NK cell function, and brief, acute distress may activate and mobilize NK cells - likely through pathways overlapping with EE (72).

\section{IMPLICATIONS OF ENVIRONMENTAL ENRICHMENT FOR HUMAN HEALTH}

As we have explored, EE is a housing model that confers beneficial and protective effects on animal health (illustrated in Figure 2). How then can this understanding of EE be applied to human health? Concerns frequently arise related to the translatability of EE research to clinical settings, which we will briefly address here. This topic is discussed elsewhere, as well as in these reviews (73-75).

At the forefront among them is the concern about what "enrichment" entails in the context of humans and human disease. As described above, EE is species-specific and multifactorial. Many beneficial effects likely result from the overlap of several components. Interventions designed to elicit species-typical behavior for humans through enrichment may need to address: culture, art/music, higher order social structures, kinship/relationships, life routine, living space, and diet, just to name a few. These are each worth addressing and clearly have complex impacts on health outcomes. It is not clear that these dimensions of human experience correspond exactly to the features of EE known to act in mouse models, but they do relate to features such as sensory and spatial navigation, cognitive demand, social interaction, and physical activity. Engaging these is generally believed to be beneficial for our health as nonpharmaceutical interventions. Our work and others' have shown that there exist robust biological pathways, otherwise not at play in standard environments, which are activated as a result of EE.

Another concern that arises is whether variation in animal exposures to components of EE during EE diminishes its validity as a model. Differences in outcomes may arise based on different experimental EE paradigms or different lived experiences among animals within any complex social and physical environment. This concern has been identified repeatedly, and studies addressing it frequently show reliability and reproducibility in $\mathrm{EE}$ (76-78). Basic standard environment features like bedding, housing density, temperature, and ambient noise all contribute to outcome variation with much less concern from the scientific audience, perhaps due to less awareness about welfare and husbandry needs (79). Humans are also varied, in terms of their genetics, their experiences, and their life history. Some researchers have proposed that because of the complexity and variation of human experiences, EE serves as a better baseline for our animal models when making inferences to human biology $(6,80)$.

The potential space for such EE to overlap in human laboratory studies and human clinical interventions is large. For example, given our knowledge of the impacts of environment and biology, changes to the environment of patients receiving care could potentially be implemented to improve well-being and health outcomes. Specific environments which may contribute enrichment for humans are still being explored. One study investigated features that constitute an "enriched environment" 


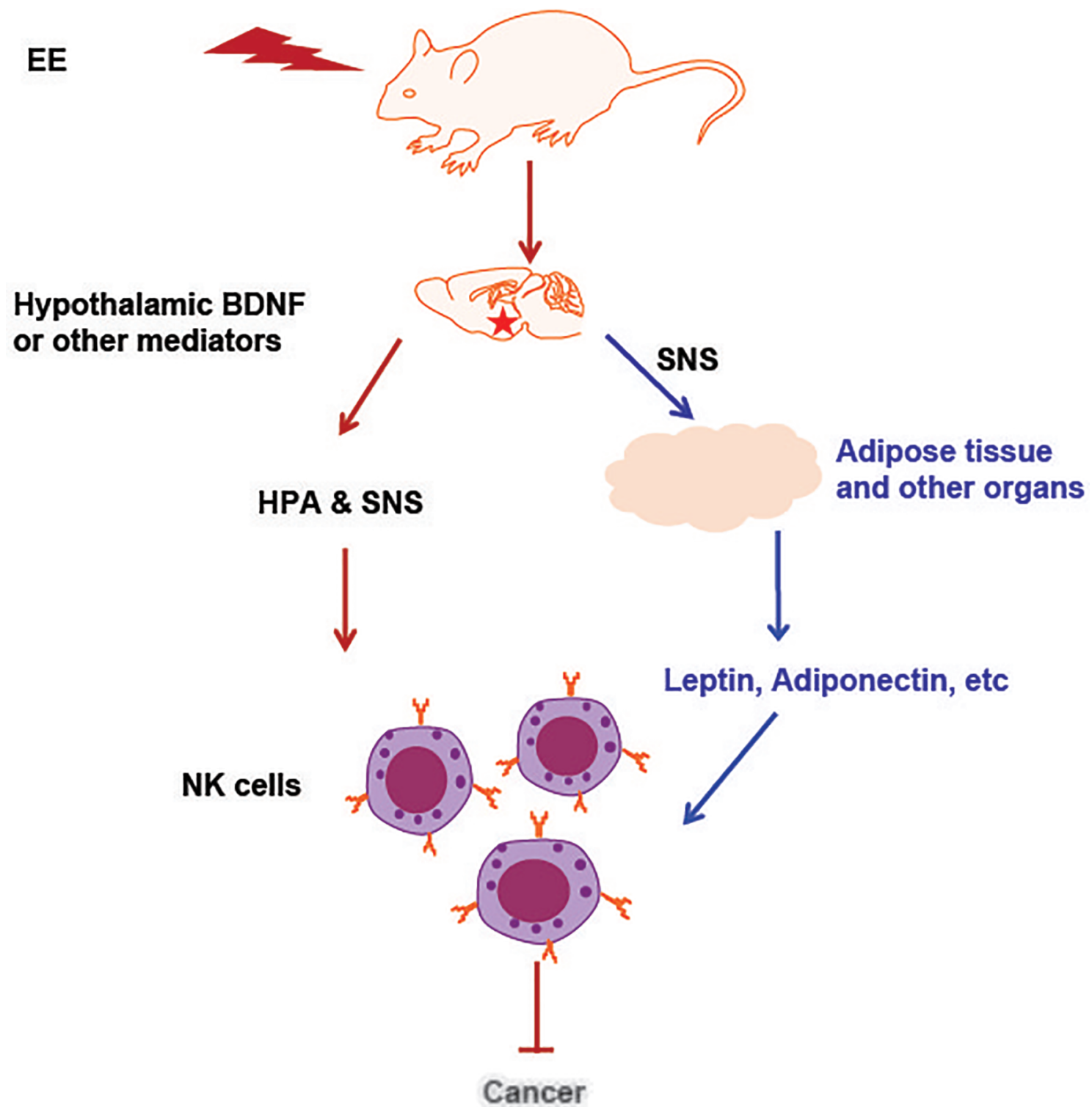

FIGURE 2 | An illustration of NK cell activation and cancer inhibition induced by EE. The induction of hypothalamic BDNF or other brain mediator molecules in response to environmental stimuli leads to the activation of the SNS and HPA axes, which can directly act on NK cells. Another pathway is that EE impacted organs with endocrine function secrete adipokines, cytokines or hormones and subsequently act on NK cells that residing in the organ. The adipokines or cytokines also enter circulation, reach the distant organs and regulate NK cells there. All these effects contribute to EE induced immune protection against cancer and other diseases.

for people and identified associations between geographical properties and brain structure (81). In that study, living close to forests may be viewed as EE for humans. Due to the increased complexity of physical, social, and psychological factors contributing to the health of humans compared to mice, and given the wider scope of a humans' life compared to that of a laboratory mouse, we expect that a kind of EE for humans includes but is not limited to geographical features. Despite advances in the understanding of EE, more studies need to be performed to apply an EE housing framework to human health.

Attempts to translate EE-mediated therapy that originated in animal models into humans remain in their infancy. Three clinical trials by Woo and Leon are among the first examples of direct translation of EE in animal models of autism spectrum disorder (ASD) to clinical studies (82-84). These randomized clinical trials have shown that EE in the form of Sensory Enrichment Therapy is capable of ameliorating symptoms of ASD. EE has also been shown to improve the symptoms of children with Rett syndrome (85). These studies provide a clear example of how preclinical studies in animal models of brain disorders can directly inform clinical investigations and trials.

Moreover, the health-promoting mechanisms of EE outlined above, including activating hypothalamic BDNF, or utilizing IL-15-induced NK cell maturation, can be translated into 
therapeutics. Hypothalamic BDNF plays a critical role in maintaining energy balance $(86,87)$. Genome-wide association studies have found that BDNF is one of 18 genetic loci associated with body mass index $(88,89)$. Haploinsufficiency for BDNF or its receptor TrkB is linked with hyperphagia and obesity (90-92). We have developed a molecular therapy and demonstrated the efficacy and safety of hypothalamic BDNF gene therapy in diet-induced and genetic models of obesity as well as aging mice of normal weight (93-96). In light of hypothalamic BDNF mediating the immunomodulating effect of EE, it will be interesting to explore targeting hypothalamic BDNF as an immune therapeutic. With regard to IL-15, we have developed a novel rAAV vector to overexpress IL-15/IL-15R $\alpha$ specifically in the adipose tissue. A single intraperitoneal injection of IL-15/IL-15R $\alpha$ vector at low dose results in expansion of $\mathrm{NK}$ cell in adipose tissue and enhanced NK activity in tumor-bearing animals leading to survival benefit (97). In addition, EE enhances NK cell antitumor immunity via regulation of NKG2D and CCR5 (39), which may be utilized in the genetic engineering of NK cells for enhanced antitumor function. As more mechanisms underlying EE-induced NK regulation are found, we expect to uncover further targets with translational potential. These preclinical data might stimulate interest in translational studies in human disease.

\section{REFERENCES}

1. Council NR. Recognition and Alleviation of Distress in Laboratory Animals. Washington (DC): National Academies Press (2008).

2. Milsum JH. A Model of the Eustress System for Health/Illness. Behav Sci (1985) 30:179-86. doi: 10.1002/bs.3830300402

3. Selye H. Distress, Psychopathology of Human Adaptation. Berlin (Germany): Springer (1976). p. 137-46.

4. Nithianantharajah J, Hannan AJ. Enriched Environments, ExperienceDependent Plasticity and Disorders of the Nervous System. Nat Rev Neurosci (2006) 7:697-709. doi: 10.1038/nrn1970

5. Diamond MC, Krech D, Rosenzweig MR. The Effects of an Enriched Environment on the Histology of the Rat Cerebral Cortex. J Comp Neurol (1964) 123:111-9. doi: 10.1002/cne.901230110

6. Kempermann G. Environmental Enrichment, New Neurons and the Neurobiology of Individuality. Nat Rev Neurosci (2019) 20:235-45. doi: 10.1038/s41583-019-0120-x

7. Singhal G, Morgan J, Jawahar MC, Corrigan F, Jaehne EJ, Toben C, et al. Duration of Environmental Enrichment Determines Astrocyte Number and Cervical Lymph Node T Lymphocyte Proportions But Not the Microglial Number in Middle-Aged C57bl/6 Mice. Front Cell Neurosci (2020) 14:57. doi: $10.3389 /$ fncel.2020.00057

8. Arranz L, De Castro NM, Baeza I, Maté I, Viveros MP, de la Fuente M. Environmental Enrichment Improves Age-Related Immune System Impairment: Long-Term Exposure Since Adulthood Increases Life Span in Mice. Rejuvenation Res (2010) 13:415-28. doi: 10.1089/rej.2009.0989

9. Zhao X, Rondón-Ortiz AN, Lima EP, Puracchio M, Roderick RC, Kentner AC. Therapeutic Efficacy of Environmental Enrichment on Behavioral, Endocrine, and Synaptic Alterations in an Animal Model of Maternal Immune Activation. Brain Behav Immunity Health (2020) 3:100043. doi: 10.1016/j.bbih.2020.100043

10. Ball N, Mercado E, Orduña I. Enriched Environments as a Potential Treatment for Developmental Disorders: A Critical Assessment. Front Psychol (2019) 10:466. doi: 10.3389/fpsyg.2019.00466

11. Van Praag H, Kempermann G, Gage FH. Neural Consequences of Enviromental Enrichment. Nat Rev Neurosci (2000) 1:191-8. doi: 10.1038/ 35044558
It would be misguided to over-interpret findings from animal studies in terms of the translatability of EE research to human conditions. With regard to immune regulatory effects of $\mathrm{EE}$, the majority of current research focuses on characterizing immune phenotypes in animal models and elucidating the underlying mechanisms. Our discussions on the implications of EE for human health and disease are somewhat speculative, but aim to stimulate interest in research of this area. On the other hand, appreciation of the complex environmental impacts on immunity is important for conducting and interpreting preclinical studies. As such, $\mathrm{EE}$ can serve as a valuable paradigm.

\section{AUTHOR CONTRIBUTIONS}

RX, SA, MC, and LC wrote and revised the manuscript. All authors contributed to the article and approved the submitted version.

\section{FUNDING}

This work was supported by NIH grants CA166590 and AG041250 to LC, and CA210087 and CA163205 to MC.

12. Hebb D. The Effects of Early Experience on Problem-Solving at Maturity. Am Psychol (1947) 2:306-7.

13. Slater AM, Cao L. A Protocol for Housing Mice in an Enriched Environment. J Vis $\operatorname{Exp}$ (2015) 100:e52874. doi: 10.3791/52874

14. Fischer A. Environmental Enrichment as a Method to Improve Cognitive Function. What can We Learn From Animal Models? Neuroimage (2016) 131:42-7. doi: 10.1016/j.neuroimage.2015.11.039

15. Cao L, Liu X, Lin EJ, Wang C, Choi EY, Riban V, et al. Environmental and Genetic Activation of a Brain-Adipocyte BDNF/leptin Axis Causes Cancer Remission and Inhibition. Cell (2010) 142:52-64. doi: 10.1016/j.cell.2010.05.029

16. McMurphy T, Huang W, Queen NJ, Ali S, Widstrom KJ, Liu X, et al. Implementation of Environmental Enrichment After Middle Age Promotes Healthy Aging. Aging (Albany NY) (2018) 10:1698-721. doi: 10.18632/ aging.101502

17. Li G, Gan Y, Fan Y, Wu Y, Lin H, Song Y, et al. Enriched Environment Inhibits Mouse Pancreatic Cancer Growth and Down-Regulates the Expression of Mitochondria-Related Genes in Cancer Cells. Sci Rep (2015) 5:7856-6. doi: 10.1038/srep07856

18. Cao L, Choi EY, Liu X, Martin A, Wang C, Xu X, et al. White to Brown Fat Phenotypic Switch Induced by Genetic and Environmental Activation of a Hypothalamic-Adipocyte Axis. Cell Metab (2011) 14:324-38. doi: 10.1016/ j.cmet.2011.06.020

19. Rosenzweig MR, Bennett EL, Hebert M, Morimoto H. Social Grouping Cannot Account for Cerebral Effects of Enriched Environments. Brain Res (1978) 153:563-76. doi: 10.1016/0006-8993(78)90340-2

20. Suzuki K, Tagami K. Voluntary Wheel-Running Exercise Enhances AntigenSpecific Antibody-Producing Splenic B Cell Response and Prolongs IgG HalfLife in the Blood. Eur J Appl Physiol (2005) 94:514-9. doi: 10.1007/s00421005-1378-4

21. Lu Y-P, Lou Y-R, Nolan B, Peng Q-Y, Xie J-G, Wagner GC, et al. Stimulatory Effect of Voluntary Exercise or Fat Removal (Partial Lipectomy) on Apoptosis in the Skin of UVB Light-Irradiated Mice. Proc Natl Acad Sci (2006) 103:16301-6. doi: 10.1073/pnas.0607789103

22. Moreno-Jiménez EP, Jurado-Arjona J, Avila J, Llorens Martín M. The Social Component of Environmental Enrichment Is a Pro-Neurogenic Stimulus in Adult c57BL6 Female Mice. Front Cell Dev Biol (2019) 7:62. doi: 10.3389/ fcell.2019.00062 
23. Jankowsky JL, Melnikova T, Fadale DJ, Xu GM, Slunt HH, Gonzales V, et al. Environmental Enrichment Mitigates Cognitive Deficits in a Mouse Model of Alzheimer's Disease. J Neurosci (2005) 25:5217-24. doi: 10.1523/ JNEUROSCI.5080-04.2005

24. Stuart KE, King AE, Fernandez-Martos CM, Summers MJ, Vickers JC. Environmental Novelty Exacerbates Stress Hormones and $A \beta$ Pathology in an Alzheimer's Model. Sci Rep (2017) 7:1-7. doi: 10.1038/s41598-017-03016-0

25. Ferchmin P, Bennett EL, Rosenzweig MR. Direct Contact With Enriched Environment Is Required to Alter Cerebral Weights in Rats. J Comp Physiol Psychol (1975) 88:360. doi: 10.1037/h0076175

26. Bergin SM, Xiao R, Huang W, Judd CRT, Liu X, Mansour AG, et al. Environmental Activation of a Hypothalamic BDNF-adipocyte IL-15 Axis Regulates Adipose-Natural Killer Cells. Brain Behav Immun (2021) 95. doi: 10.1016/j.bbi.2021.05.005

27. Xiao R, Bergin SM, Huang W, Slater AM, Liu X, Judd RT, et al. Environmental and Genetic Activation of Hypothalamic Bdnf Modulates T-Cell Immunity to Exert an Anticancer Phenotype. Cancer Immunol Res (2016) 4:488-97. doi: 10.1158/2326-6066.CIR-15-0297

28. Xiao R, Bergin SM, Huang W, Mansour AG, Liu X, Judd RT, et al. Enriched Environment Regulates Thymocyte Development and Alleviates Experimental Autoimmune Encephalomyelitis in Mice. Brain Behav Immun (2019) 75:137-48. doi: 10.1016/j.bbi.2018.09.028

29. Brod S, Gobbetti T, Gittens B, Ono M, Perretti M, D’Acquisto F. The Impact of Environmental Enrichment on the Murine Inflammatory Immune Response. JCI Insight (2017) 2. doi: 10.1172/jci.insight.90723

30. Garofalo S, D'Alessandro G, Chece G, Brau F, Maggi L, Rosa A, et al. Enriched Environment Reduces Glioma Growth Through Immune and non-Immune Mechanisms in Mice. Nat Commun (2015) 6:6623. doi: 10.1038/ncomms7623

31. Schedlowski M, Jacobs R, Stratmann G, Richter S, Hädicke A, Tewes U, et al. Changes of Natural Killer Cells During Acute Psychological Stress. J Clin Immunol (1993) 13:119-26. doi: 10.1007/BF00919268

32. Long EO, Rajagopalan S. Stress Signals Activate Natural Killer Cells. J Exp Med (2002) 196:1399-402. doi: 10.1084/jem.20021747

33. Chiossone L, Chaix J, Fuseri N, Roth C, Vivier E, Walzer T. Maturation of Mouse NK Cells Is a 4-Stage Developmental Program. Blood J Am Soc Hematol (2009) 113:5488-96. doi: 10.1182/blood-2008-10-187179

34. Nair S, Fang M, Sigal LJ. The Natural Killer Cell Dysfunction of Aged Mice Is Due to the Bone Marrow Stroma and Is Not Restored by IL-15/IL-15Ralpha Treatment. Aging Cell (2015) 14:180-90. doi: 10.1111/acel.12291

35. Meng Z, Liu T, Song Y, Wang Q, Xu D, Jiang J, et al. Exposure to an Enriched Environment Promotes the Terminal Maturation and Proliferation of Natural Killer Cells in Mice. Brain Behav Immun (2019) 77:150-60. doi: 10.1016/ j.bbi.2018.12.017

36. Fu B, Wang F, Sun R, Ling B, Tian Z, Wei H. CD11b and CD27 Reflect Distinct Population and Functional Specialization in Human Natural Killer Cells. Immunology (2011) 133:350-9. doi: 10.1111/j.1365-2567.2011.03446.x

37. Mansour AG, Xiao R, Bergin SM, Huang W, Chrislip LA, Zhang J, et al. Enriched Environment Enhances NK Cell Maturation Through Hypothalamic BDNF in Male Mice. Eur J Immunol (2020) 51. doi: 10.1002/ eji.201948358

38. Benaroya-Milshtein N, Hollander N, Apter A, Kukulansky T, Raz N, Wilf A, et al. Environmental Enrichment in Mice Decreases Anxiety, Attenuates Stress Responses and Enhances Natural Killer Cell Activity. Eur J Neurosci (2004) 20:1341-7. doi: 10.1111/j.1460-9568.2004.03587.x

39. Song Y, Gan Y, Wang Q, Meng Z, Li G, Shen Y, et al. Enriching the Housing Environment for Mice Enhances Their NK Cell Antitumor Immunity Via Sympathetic Nerve-Dependent Regulation of NKG2D and CCR5. Cancer Res (2017) 77:1611-22. doi: 10.1158/0008-5472.CAN-16-2143

40. Wensveen FM, Jelencic V, Polic B. Nkg2d: A Master Regulator of Immune Cell Responsiveness. Front Immunol (2018) 9:441. doi: 10.3389/fimmu.2018.00441

41. Alter G, Malenfant JM, Altfeld M. CD107a as a Functional Marker for the Identification of Natural Killer Cell Activity. J Immunol Methods (2004) 294:15-22. doi: 10.1016/j.jim.2004.08.008

42. Aktas E, Kucuksezer UC, Bilgic S, Erten G, Deniz G. Relationship Between CD107a Expression and Cytotoxic Activity. Cell Immunol (2009) 254:149-54. doi: 10.1016/j.cellimm.2008.08.007

43. Takai D, Abe A, Miura H, Tanaka S, Komura J-I. Minimum Environmental Enrichment Is Effective in Activating Antitumor Immunity to Transplanted
Tumor Cells in Mice. Exp Anim (2019) 4:19-0055. doi: 10.1538/expanim.190055

44. Jaillon S, Berthenet K, Garlanda C. Sexual Dimorphism in Innate Immunity. Clin Rev Allergy Immunol (2019) 56:308-21. doi: 10.1007/s12016-017-8648-x

45. Milner JJ, Beck MA. The Impact of Obesity on the Immune Response to Infection. Proc Nutr Soc (2012) 71:298-306. doi: 10.1017/S0029665112000158

46. Gillum TL, Kuennen MR, Schneider S, Moseley P. A Review of Sex Differences in Immune Function After Aerobic Exercise. Exerc Immunol Rev (2011) 17:104-21.

47. Castelo-Branco C, Soveral I. The Immune System and Aging: A Review. Gynecol Endocrinol (2014) 30:16-22. doi: 10.3109/09513590.2013.852531

48. Manley K, Han W, Zelin G, Lawrence DA. Crosstalk Between the Immune, Endocrine, and Nervous Systems in Immunotoxicology. Curr Opin Toxicol (2018) 10:37-45. doi: 10.1016/j.cotox.2017.12.003

49. Exton MS, Schedlowski M. Crosstalk Between the Brain and Immune System. Trends Immunol (2001) 22:282-3. doi: 10.1016/S1471-4906(01)01901-9

50. Foglesong GD, Huang W, Liu X, Slater AM, Siu J, Yildiz V, et al. Role of Hypothalamic VGF in Energy Balance and Metabolic Adaption to Environmental Enrichment in Mice. Endocrinology (2016) 2016:34-46. doi: 10.1210/en.2015-1627

51. Garofalo S, Porzia A, Mainiero F, Di Angelantonio S, Cortese B, Basilico B, et al. Environmental Stimuli Shape Microglial Plasticity in Glioma. Elife (2017) 6. doi: 10.7554/eLife.33415

52. Mehta S, Ughade S, Mehta A, Mehta A, Mathur G, Mehta A. Correlation Between Cancer Phobia Anxiety Disorder and Recurrence in Breast Cancer Patients: Five Year Retrospective Study in an Indian Setting. Psycho-Oncology (2014) 23:188-8. WILEY-BLACKWELL 111 RIVER ST, HOBOKEN 070305774 , NJ USA.

53. Ménard C, Pfau ML, Hodes GE, Russo SJ. Immune and Neuroendocrine Mechanisms of Stress Vulnerability and Resilience. Neuropsychopharmacology (2017) 42:62-80. doi: 10.1038/npp.2016.90

54. Cao L, During MJ. What Is the Brain-Cancer Connection? Annu Rev Neurosci (2012) 35:331-45. doi: 10.1146/annurev-neuro-062111-150546

55. Klein R, Wilson S, Dzielak D, Yang W-H, Viveros O. Opioid Peptides and Noradrenaline Co-Exist in Large Dense-Cored Vesicles From Sympathetic Nerve. Neuroscience (1982) 7:2255-61. doi: 10.1016/0306-4522(82)90135-X

56. Nance DM, Sanders VM. Autonomic Innervation and Regulation of the Immune System (1987-2007). Brain Behav Immun (2007) 21:736-45. doi: 10.1016/j.bbi.2007.03.008

57. Kin NW, Sanders VM. It Takes Nerve to Tell $\mathrm{T}$ and B Cells What to do. J Leukocyte Biol (2006) 79:1093-104. doi: 10.1189/jlb.1105625

58. Liberman AC, Budziñski ML, Sokn C, Gobbini RP, Steininger A, Arzt E. Regulatory and Mechanistic Actions of Glucocorticoids on $\mathrm{T}$ and Inflammatory Cells. Front Endocrinol (2018) 9:235. doi: 10.3389/ fendo.2018.00235

59. Miller AH, Spencer RL, Pearce BD, Pisell TL, Azrieli Y, Tanapat P, et al. Glucocorticoid Receptors Are Differentially Expressed in the Cells and Tissues of the Immune System. Cell Immunol (1998) 186:45-54. doi: 10.1006/ cimm.1998.1293

60. Capellino S, Claus M, Watzl C. Regulation of Natural Killer Cell Activity by Glucocorticoids, Serotonin, Dopamine, and Epinephrine. Cell Mol Immunol (2020) 17:705-11. doi: 10.1038/s41423-020-0477-9

61. Bernotiene E, Palmer G, Gabay C. The Role of Leptin in Innate and Adaptive Immune Responses. Arthritis Res Ther (2006) 8:217. doi: 10.1186/ar2004

62. Luo Y, Liu M. Adiponectin: A Versatile Player of Innate Immunity. J Mol Cell Biol (2016) 8:120-8. doi: 10.1093/jmcb/mjw012

63. Carbone F, La Rocca C, Matarese G. Immunological Functions of Leptin and Adiponectin. Biochimie (2012) 94:2082-8. doi: 10.1016/j.biochi.2012.05.018

64. Ali S, Liu X, Queen NJ, Patel RS, Wilkins RK, Mo X, et al. Long-Term Environmental Enrichment Affects Microglial Morphology in Middle Age Mice. Aging (Albany NY) (2019) 11:2388-402. doi: 10.18632/aging.101923

65. Ali S, Mansour AG, Huang W, Queen NJ, Mo X, Anderson JM, et al. CSF1R Inhibitor PLX5622 and Environmental Enrichment Additively Improve Metabolic Outcomes in Middle-Aged Female Mice. Aging (Albany NY) (2020) 12:2101-22. doi: 10.18632/aging.102724

66. Ranson T, Vosshenrich CA, Corcuff E, Richard O, Müller W, Di Santo JP. IL-15 Is an Essential Mediator of Peripheral NK-cell Homeostasis. Blood (2003) 101:4887-93. doi: 10.1182/blood-2002-11-3392 
67. Carson WE, Giri JG, Lindemann M, Linett ML, Ahdieh M, Paxton R, et al. Interleukin (IL) 15 Is a Novel Cytokine That Activates Human Natural Killer Cells Via Components of the IL-2 Receptor. J Exp Med (1994) 180:1395-403. doi: $10.1084 /$ jem.180.4.1395

68. Pedersen L, Idorn M, Olofsson GH, Lauenborg B, Nookaew I, Hansen RH, et al. Voluntary Running Suppresses Tumor Growth Through Epinephrineand IL-6-Dependent Nk Cell Mobilization and Redistribution. Cell Metab (2016) 23:554-62. doi: 10.1016/j.cmet.2016.01.011

69. Chen P, Fan Y, Li Y, Sun Z, Bissette G, Zhu MY. Chronic Social Defeat UpRegulates Expression of Norepinephrine Transporter in Rat Brains. Neurochem Int (2012) 60:9-20. doi: 10.1016/j.neuint.2011.11.003

70. Hanke ML, Powell ND, Stiner LM, Bailey MT, Sheridan JF. Beta Adrenergic Blockade Decreases the Immunomodulatory Effects of Social Disruption Stress. Brain Behav Immun (2012) 26:1150-9. doi: 10.1016/j.bbi.2012.07.011

71. Hunzeker J, Padgett DA, Sheridan PA, Dhabhar FS, Sheridan JF. Modulation of Natural Killer Cell Activity by Restraint Stress During an Influenza A/PR8 Infection in Mice. Brain Behav Immun (2004) 18:526-35. doi: 10.1016/ j.bbi.2003.12.010

72. Dragos D, Tanasescu MD. The Effect of Stress on the Defense Systems. J Med Life (2010) 3:10-8.

73. Queen NJ, Hassan QN2nd, Cao L. Improvements to Healthspan Through Environmental Enrichment and Lifestyle Interventions: Where Are We Now? Front Neurosci (2020) 14:605. doi: 10.3389/fnins.2020.00605

74. McDonald MW, Hayward KS, Rosbergen ICM, Jeffers MS, Corbett D. Is Environmental Enrichment Ready for Clinical Application in Human PostStroke Rehabilitation? Front Behav Neurosci (2018) 12:135. doi: 10.3389/ fnbeh.2018.00135

75. Burrows EL, Hannan AJ. Towards Environmental Construct Validity in Animal Models of CNS Disorders: Optimizing Translation of Preclinical Studies. CNS Neurol Disord Drug Targets (2013) 12:587-92. doi: 10.2174/ 1871527311312050007

76. Toth LA, Kregel K, Leon L, Musch TI. Environmental Enrichment of Laboratory Rodents: The Answer Depends on the Question. Comp Med (2011) 61:314-21.

77. Wolfer DP, Litvin O, Morf S, Nitsch RM, Lipp HP, Wurbel H. Laboratory Animal Welfare: Cage Enrichment and Mouse Behaviour. Nature (2004) 432:821-2. doi: 10.1038/432821a

78. Kentner AC, Speno AV, Doucette J, Roderick RC. The Contribution of Environmental Enrichment to Phenotypic Variation in Mice and Rats. eNeuro (2021) 8. doi: 10.1101/2020.07.11.198705

79. Toth LA. The Influence of the Cage Environment on Rodent Physiology and Behavior: Implications for Reproducibility of Pre-Clinical Rodent Research. Exp Neurol (2015) 270:72-7. doi: 10.1016/j.expneurol.2015.04.010

80. Burrows EL, McOmish CE, Hannan AJ. Gene-Environment Interactions and Construct Validity in Preclinical Models of Psychiatric Disorders. Prog Neuropsychopharmacol Biol Psychiatry (2011) 35:1376-82. doi: 10.1016/ j.pnpbp.2010.12.011

81. Kühn S, Düzel S, Eibich P, Krekel C, Wüstemann H, Kolbe J, et al. In Search of Features That Constitute an "Enriched Environment" in Humans: Associations Between Geographical Properties and Brain Structure. Sci Rep (2017) 7:11920. doi: 10.1038/s41598-017-12046-7

82. Woo CC, Leon M. Environmental Enrichment as an Effective Treatment for Autism: A Randomized Controlled Trial. Behav Neurosci (2013) 127:487-97. doi: $10.1037 / \mathrm{a} 0033010$

83. Woo CC, Donnelly JH, Steinberg-Epstein R, Leon M. Environmental Enrichment as a Therapy for Autism: A Clinical Trial Replication and Extension. Behav Neurosci (2015) 129:412-22. doi: 10.1037/bne0000068

84. Aronoff E, Hillyer R, Leon M. Environmental Enrichment Therapy for Autism: Outcomes With Increased Access. Neural Plast (2016) 2016:2734915. doi: 10.1155/2016/2734915
85. Downs J, Rodger J, Li C, Tan X, Hu N, Wong K, et al. Environmental Enrichment Intervention for Rett Syndrome: An Individually Randomised Stepped Wedge Trial. Orphanet J Rare Dis (2018) 13:3. doi: 10.1186/s13023017-0752-8

86. Xu B, Goulding EH, Zang K, Cepoi D, Cone RD, Jones KR, et al. BrainDerived Neurotrophic Factor Regulates Energy Balance Downstream of Melanocortin-4 Receptor. Nat Neurosci (2003) 6:736-42. doi: 10.1038/nn1073

87. Xu B, Xie X. Neurotrophic Factor Control of Satiety and Body Weight. Nat Rev Neurosci (2016) 17:282-92. doi: 10.1038/nrn.2016.24

88. Speliotes EK, Willer CJ, Berndt SI, Monda KL, Thorleifsson G, Jackson AU, et al. Association Analyses of 249,796 Individuals Reveal 18 New Loci Associated With Body Mass Index. Nat Genet (2010) 42:937-48. doi: 10.1038/ng.686

89. Jiao H, Arner P, Hoffstedt J, Brodin D, Dubern B, Czernichow S, et al. Genome Wide Association Study Identifies KCNMA1 Contributing to Human Obesity. BMC Med Genomics (2011) 4:51. doi: 10.1186/1755-8794-4-51

90. Gray J, Yeo GS, Cox JJ, Morton J, Adlam AL, Keogh JM, et al. Hyperphagia, Severe Obesity, Impaired Cognitive Function, and Hyperactivity Associated With Functional Loss of One Copy of the Brain-Derived Neurotrophic Factor (BDNF) Gene. Diabetes (2006) 55:3366-71. doi: 10.2337/db06-0550

91. Eliassen AH, Hankinson SE. Endogenous Hormone Levels and Risk of Breast, Endometrial and Ovarian Cancers: Prospective Studies. Adv Exp Med Biol (2008) 630:148-65. doi: 10.1007/978-0-387-78818-0_10

92. Yeo GS, Connie Hung CC, Rochford J, Keogh J, Gray J, Sivaramakrishnan S, et al. A De Novo Mutation Affecting Human TrkB Associated With Severe Obesity and Developmental Delay. Nat Neurosci (2004) 7:1187-9. doi: 10.1038/nn1336

93. Cao L, Lin EJ, Cahill MC, Wang C, Liu X, During MJ. Molecular Therapy of Obesity and Diabetes by a Physiological Autoregulatory Approach. Nat Med (2009) 15:447-54. doi: 10.1038/nm.1933

94. Liu X, McMurphy T, Xiao R, Slater A, Huang W, Cao L. Hypothalamic Gene Transfer of BDNF Inhibits Breast Cancer Progression and Metastasis in Middle Age Obese Mice. Mol Ther J Am Soc Gene Ther (2014) 22. doi: $10.1038 / \mathrm{mt} .2014 .45$

95. McMurphy T, Huang W, Liu X, Siu JJ, Queen NJ, Xiao R, et al. Hypothalamic Gene Transfer of BDNF Promotes Healthy Aging in Mice. Aging Cell (2019) 18:e12846. doi: 10.1111/acel.12846

96. Siu JJ, Queen NJ, Liu X, Huang W, McMurphy T, Cao L. Molecular Therapy of Melanocortin-4-Receptor Obesity by an Autoregulatory Bdnf Vector. Mol Ther Methods Clin Dev (2017) 7:83-95. doi: 10.1016/j.omtm.2017.09.005

97. Xiao R, Mansour AG, Huang W, Chrislip LA, Wilkins RK, Queen NJ, et al. Adipocytes: A Novel Target for IL-15/IL-15Ralpha Cancer Gene Therapy. Mol Ther J Am Soc Gene Ther (2019) 27:922-32. doi: 10.1016/j.ymthe.2019.02.011

Conflict of Interest: The authors declare that the research was conducted in the absence of any commercial or financial relationships that could be construed as a potential conflict of interest.

Publisher's Note: All claims expressed in this article are solely those of the authors and do not necessarily represent those of their affiliated organizations, or those of the publisher, the editors and the reviewers. Any product that may be evaluated in this article, or claim that may be made by its manufacturer, is not guaranteed or endorsed by the publisher.

Copyright (C) 2021 Xiao, Ali, Caligiuri and Cao. This is an open-access article distributed under the terms of the Creative Commons Attribution License (CC BY). The use, distribution or reproduction in other forums is permitted, provided the original author(s) and the copyright owner(s) are credited and that the original publication in this journal is cited, in accordance with accepted academic practice. No use, distribution or reproduction is permitted which does not comply with these terms. 